Supporting Information

\title{
Synergistic Cyanamide Functionalization and Charge-Induced Activation of Nickel/Carbon Nitride for Enhanced Selective Photoreforming of Ethanol
}

Denny Gunawan, Cui Ying Toe*, Priyank Kumar, Jason Scott, and Rose Amal*

Particles and Catalysis Research Group, School of Chemical Engineering, The University of New South Wales (UNSW), Sydney, NSW 2052, Australia

*Email: c.toe@unsw.edu.au, $\underline{\text { r.amal@unsw.edu.au }}$ 


\section{Supporting Methods}

\section{Synthesis of Annealed Carbon Nitride and Oxygen-Functionalized Carbon Nitride}

Annealed carbon nitride (a-CN) was synthesized by annealing pristine carbon nitride (p-CN) at $400^{\circ} \mathrm{C}$ for $1 \mathrm{~h}$ and then at $500^{\circ} \mathrm{C}$ for 30 min under Ar. ${ }^{1}$ Oxygen-functionalized carbon nitride $(\mathrm{O}-\mathrm{CN})$ was prepared by calcining $\mathrm{p}-\mathrm{CN}$ at $530^{\circ} \mathrm{C}$ for $2 \mathrm{~h}$ under air. ${ }^{2}$

\section{Photoelectrochemical Measurements}

Photoelectrochemical (PEC) characterization was carried out in a PTFE-lined PEC cell equipped with a quartz window for illumination. Phosphate buffer (1 M, pH 6.3) with $10 \%$ ethanol was used as electrolyte, $\mathrm{Ag} / \mathrm{AgCl}$ electrode in saturated $\mathrm{KCl}$ solution was used as the reference electrode $(0.197 \mathrm{~V} v s \mathrm{SHE})$, and Pt foil was used as the counter electrode. Prior to the measurement, the cell was purged with $\mathrm{N}_{2}$ through a porous glass frit. The time-dependent open circuit potential (OCP) profiles were then measured on an Autolab potentiostat (Model PGSTAT302N). The light source was a Newport solar simulator which is set to AM1.5G $\left(100 \mathrm{~mW} \mathrm{~cm}^{-2}\right)$. The working electrodes were prepared as follows. A $10 \mathrm{mg}$ of sample was ultrasonicated in $10 \mathrm{~mL}$ of ethanol for $1 \mathrm{~h}$. A $300 \mu \mathrm{L}$ of this mixture was then drop casted onto FTO slides $\left(2 \times 2 \mathrm{~cm}^{2}\right)$ and dried at $60^{\circ} \mathrm{C}$ under vacuum.

\section{Coumarine Tests for Hydroxyl Radical Detection}

Coumarin was used as a probe molecule to detect the presence of hydroxyl radicals by monitoring the formation of 7-hydroxycoumarin. ${ }^{3-4} \mathrm{In}$ a typical test, $100 \mathrm{~mL}$ of $10 \%$ ethanol solution with $1 \mathrm{mM}$ coumarin was loaded with $100 \mathrm{mg}$ of NCN-CN and sonicated for $20 \mathrm{~min}$. The suspension was then introduced into the spiral photoreactor, purged with $\mathrm{N}_{2}$, and exposed with light. After irradiation, an aliquot was withdrawn and passed through $0.22 \mu$ m nylon syringe filter to examine the fluorescence spectrum using an excitation wavelength of $335 \mathrm{~nm}$. 


\section{Zeta Potential Measurements}

The post-reaction mixtures of $\mathrm{NCN}-\mathrm{CN}, \mathrm{Ni}(1.25) / \mathrm{NCN}-\mathrm{CN}$ and $\mathrm{Ni}(3) / \mathrm{NCN}-\mathrm{CN}$ were taken from the photoreactor and ultrasonicated for $20 \mathrm{~min}$ prior to measurements. The zeta potentials of the retrieved solids in $10 \mathrm{mM} \mathrm{NaCl}$ aqueous solutions were also recorded by centrifuging the post-reaction mixtures without washing and dispersing the precipitates in $10 \mathrm{mM} \mathrm{NaCl}$ aqueous solutions via ultrasonication. All zeta potentials were recorded on Malvern Zetasizer 2000 using folded capillary zeta cells.

\section{Additional Photoluminescence Spectroscopy}

A $10 \mathrm{mg}$ of NCN-CN was first dispersed in $10 \mathrm{~mL}$ of $10 \%$ ethanol solution with different concentrations of $\mathrm{Ni}\left(\mathrm{NO}_{3}\right)_{2} \cdot 6 \mathrm{H}_{2} \mathrm{O}(0,0.5,1$, and $3 \mathrm{mM})$ via sonication for $20 \mathrm{~min}$. The mixture was then diluted by a factor of 4 with water prior to photoluminescence (PL) spectrum acquisition.

\section{Ethanol Adsorption Experiments}

To investigate the effect of $\mathrm{Ni}^{2+}$ on ethanol adsorption, the post-reaction mixture of $\mathrm{Ni}(3) / \mathrm{NCN}-\mathrm{CN}$ was centrifuged, washed with water, and dispersed in $100 \mathrm{~mL}$ of $10 \mathrm{mM}$ ethanol aqueous solution with or without $\mathrm{Ni}\left(\mathrm{NO}_{3}\right)_{2} \cdot 6 \mathrm{H}_{2} \mathrm{O}$ addition. The mixture was then sonicated for $20 \mathrm{~min}$ and stirred for $9 \mathrm{~h}$ under dark. Finally, the mixture was filtered through $0.22 \mu$ m nylon syringe filter, mixed with $\mathrm{D}_{2} \mathrm{O}$ (volume ratio of 9:1), and analyzed by using ${ }^{1} \mathrm{H}$ NMR spectroscopy.

\section{Photoreforming Activity and Selectivity Calculations}

The $\mathrm{H}_{2}$ evolution rate, the acetaldehyde production rate, and the acetaldehyde selectivity are calculated according to Equations (S1), (S2), and (S3), respectively.

$H_{2}$ evolution rate $=\frac{n_{H_{2}}\left(t=t_{f}\right)-n_{H_{2}}\left(t=t_{0}\right)}{\left(t_{f}-t_{0}\right) \times m_{\text {cat }}}$

$\mathrm{CH}_{3} \mathrm{CHO}$ production rate $=\frac{n_{\mathrm{CH}_{3} \mathrm{CHO}}\left(t=t_{f}\right)-n_{\mathrm{CH}_{3} \mathrm{CHO}}\left(t=t_{0}\right)}{\left(t_{f}-t_{0}\right) \times m_{\text {cat }}}$

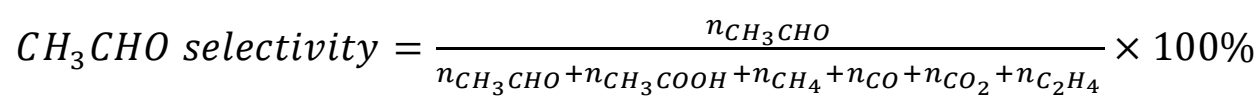

where, $n_{i}$ is the number of moles of component $i, t_{0}$ is the initial time, $t_{f}$ is the final time, and $m_{c a t}$ is the mass of catalyst. 


\section{Energy Conversion Efficiency}

Typically, energy conversion efficiency is defined as output energy per input energy. ${ }^{5}$ In photocatalytic $\mathrm{H}_{2}$ production, the input energy is the light energy which depends on the light source intensity and the irradiated area, while the output energy is the stored chemical energy of the $\mathrm{H}_{2}$ produced. The amount of $\mathrm{H}_{2}$ energy is estimated as the standard heat of combustion of $\mathrm{H}_{2}\left(\Delta H_{\text {comb }}^{0}=-286,000 \mathrm{~J} \mathrm{~mol}^{-1}\right)$. Therefore, the energy conversion efficiency of photocatalytic $\mathrm{H}_{2}$ production can be expressed as Equation (S4).

Energy conversion efficiency $=\frac{r_{\mathrm{H}_{2}} \times\left(-\Delta H_{\text {comb }}^{0}\right)}{I \times S} \times 100 \%$

where, $r_{H_{2}}$ is the $\mathrm{H}_{2}$ evolution rate $\left(\mathrm{mol} \mathrm{s}^{-1}\right), I$ is the light source intensity $\left(\sim 5 \times 10^{-3} \mathrm{~W} \mathrm{~cm}^{-2}\right)$, and $S$ is the irradiated area of the spiral photoreactor $\left(\sim 218.4 \mathrm{~cm}^{2}\right)$.

\section{Density Functional Theory Calculations}

The plane-wave Vienna Ab initio Simulation Package (VASP) code was used for density functional theory (DFT) calculations ${ }^{6-7}$ The core electrons were treated using the projector augmented wave method (PAW) method, and the Perdew-Burke-Ernzerhof (PBE) exchange-correlation functional was employed. ${ }^{8-9} \mathrm{~A}$ kinetic energy cut-off value of $500 \mathrm{eV}$ was used for wavefunctions and a gamma-point k-grid was used for surface slab calculations. All relaxations proceeded until the residual forces on atoms were less than $0.03 \mathrm{eV} / \AA$. A vacuum region greater than $10 \AA$ in the direction normal to the sheets was used to a void interactions between periodic images. In order to study the adsorption of ethanol on uncharged and charged Ni surfaces, we employed a hexagonal Ni(111) surface slab model measuring $9.81 \AA \times 9.81 \AA$. The Ni slab contained 4 atomic layers in the surface normal direction with $64 \mathrm{Ni}$ atoms. We considered two charged cases, i.e. oxidation states of +0.5 and +1.0 per unit cell to understand the effect of charging on the adsorption of ethanol. Ethanol adsorption took place via the bonding of the $\mathrm{O}$ atom of the ethanol with a surface Ni atom in the atop position. The adsorption energy of ethanol is calculated according to Equation (S5).

$E_{a d s}=E_{(e t h .+N i)}-E_{N i}-E_{(e t h .)}$

where, $E_{(e t h .+N i)}$ is the total energy of the adsorbed configuration, $E_{N i}$ is the total energy of the Ni slab alone (charged or uncharged), and $E_{(e t h .)}$ is the total energy of the ethanol molecule. 


\section{Supporting Tables}

Table S1. Comparison of the photocatalytic $\mathrm{H}_{2}$ evolution activity of Ni/NCN-CN in this work with other reported $\mathrm{Ni} /$ carbon nitride-based photocatalysts.

\begin{tabular}{|c|c|c|c|c|}
\hline Semiconductor & Cocatalyst & Substrate & $\mathrm{H}_{2}$ evolution rate $\left(\mathrm{mmol} \mathrm{h}^{-1} \mathrm{~g}^{-1}\right)$ & Ref. \\
\hline CNPS-NH ${ }_{2}$ & Ni NPs & TEOA & 1.23 & 2 \\
\hline $\mathrm{B}-\mathrm{CN}$ & Ni NPs & TEOA & 1.29 & 10 \\
\hline $\mathrm{g}-\mathrm{C}_{3} \mathrm{~N}_{4}$ & Ni NPs & TEOA & 4.32 & 11 \\
\hline $\mathrm{sg}-\mathrm{CN}$ & $\mathrm{Ni}_{2} \mathrm{P}$ NPs & TEOA & 0.33 & 12 \\
\hline $\mathrm{g}-\mathrm{CN}$ & $\mathrm{Ni} / \mathrm{Ni}_{3} \mathrm{C}$ NPs & TEOA & 1.81 & 13 \\
\hline${ }^{\mathrm{NCN}} \mathrm{CN}_{x}$ & Molecular NiP & 4-MBA & 0.76 & 14 \\
\hline $\mathrm{CN}$ & Ni-DAG SAs & Ethanol & 0.30 & 15 \\
\hline $\mathrm{NCN}-\mathrm{CN}$ & $\mathrm{Ni} N P s$ & Ethanol & 2.32 & This work \\
\hline
\end{tabular}

Table S2. Mass balance calculations of Ni during $9 \mathrm{~h}$ of photoreforming reaction on Ni/NCN-CN with different initial $\mathrm{Ni}^{2+}$ concentrations.

\begin{tabular}{ccccccc}
\hline \multirow{2}{*}{ Sample } & \multicolumn{2}{c}{ Input } & \multicolumn{2}{c}{ Ni on NCN-CN } & \multicolumn{2}{c}{ Calculated Ni in solution } \\
\cline { 2 - 6 } & $\mathrm{mM}$ & wt $\%$ & $\mathrm{mM}$ & wt $\%$ & $\mathrm{mM}$ & wt \% \\
\hline $\mathrm{Ni}(1) / \mathrm{NCN}-\mathrm{CN}$ & 1.00 & 6.00 & 0.98 & 5.87 & 0.02 & 0.13 \\
$\mathrm{Ni}(3) / \mathrm{NCN}-\mathrm{CN}$ & 3.00 & 18.00 & 1.23 & 7.40 & 1.77 & 10.60 \\
$\mathrm{Ni}(5) / \mathrm{NCN}-\mathrm{CN}$ & 5.00 & 30.00 & 1.35 & 8.10 & 3.65 & 21.90 \\
\hline
\end{tabular}


Table S3. Distributions of other carbon products for $\mathrm{NCN}-\mathrm{CN}, \mathrm{Ni}(1) / \mathrm{NCN}-\mathrm{CN}, \mathrm{Ni}(3) / \mathrm{NCN}-\mathrm{CN}$, and $\mathrm{Ni}(5) / \mathrm{NCN}-\mathrm{CN}$ after $9 \mathrm{~h}$ of reaction.

\begin{tabular}{cccccc}
\hline \multirow{2}{*}{ Sample } & \multicolumn{5}{c}{ Number of moles $(\mu \mathrm{mol})$} \\
\cline { 2 - 5 } & $\mathrm{CH}_{3} \mathrm{COOH}$ & $\mathrm{CO}_{2}$ & $\mathrm{CH}_{4}$ & $\mathrm{CO}$ & $\mathrm{C}_{2} \mathrm{H}_{4}$ \\
\hline $\mathrm{NCN}-\mathrm{CN}$ & 0.00 & 0.01 & 0.00 & 0.00 & 0.00 \\
$\mathrm{Ni}(1) / \mathrm{NCN}-\mathrm{CN}$ & 2.70 & 0.47 & 0.22 & 0.22 & 0.57 \\
$\mathrm{Ni}(3) / \mathrm{NCN}-\mathrm{CN}$ & 0.00 & 10.97 & 0.56 & 0.44 & 0.87 \\
$\mathrm{Ni}(5) / \mathrm{NCN}-\mathrm{CN}$ & 0.00 & 10.47 & 0.58 & 0.37 & 0.68 \\
\hline
\end{tabular}

Table S4. Time-dependent distributions of other carbon products for $\mathrm{Ni}(3) / \mathrm{NCN}-\mathrm{CN}$ during photoreforming stability test.

\begin{tabular}{cccccc}
\hline \multirow{2}{*}{ Time (h) } & \multicolumn{5}{c}{ Number of moles $(\mu \mathrm{mol})$} \\
\cline { 2 - 5 } & $\mathrm{CH}_{3} \mathrm{COOH}$ & $\mathrm{CO}_{2}$ & $\mathrm{CH}_{4}$ & $\mathrm{CO}$ & $\mathrm{C}_{2} \mathrm{H}_{4}$ \\
\hline 5 & 0.00 & 13.23 & 0.28 & 0.04 & 0.61 \\
9 & 0.00 & 10.97 & 0.56 & 0.44 & 0.87 \\
14 & 0.00 & 12.12 & 1.17 & 0.91 & 0.84 \\
19 & 36.30 & 13.61 & 2.08 & 1.55 & 1.02 \\
24 & 66.00 & 15.10 & 3.20 & 2.18 & 1.17 \\
\hline
\end{tabular}




\section{Supporting Figures}

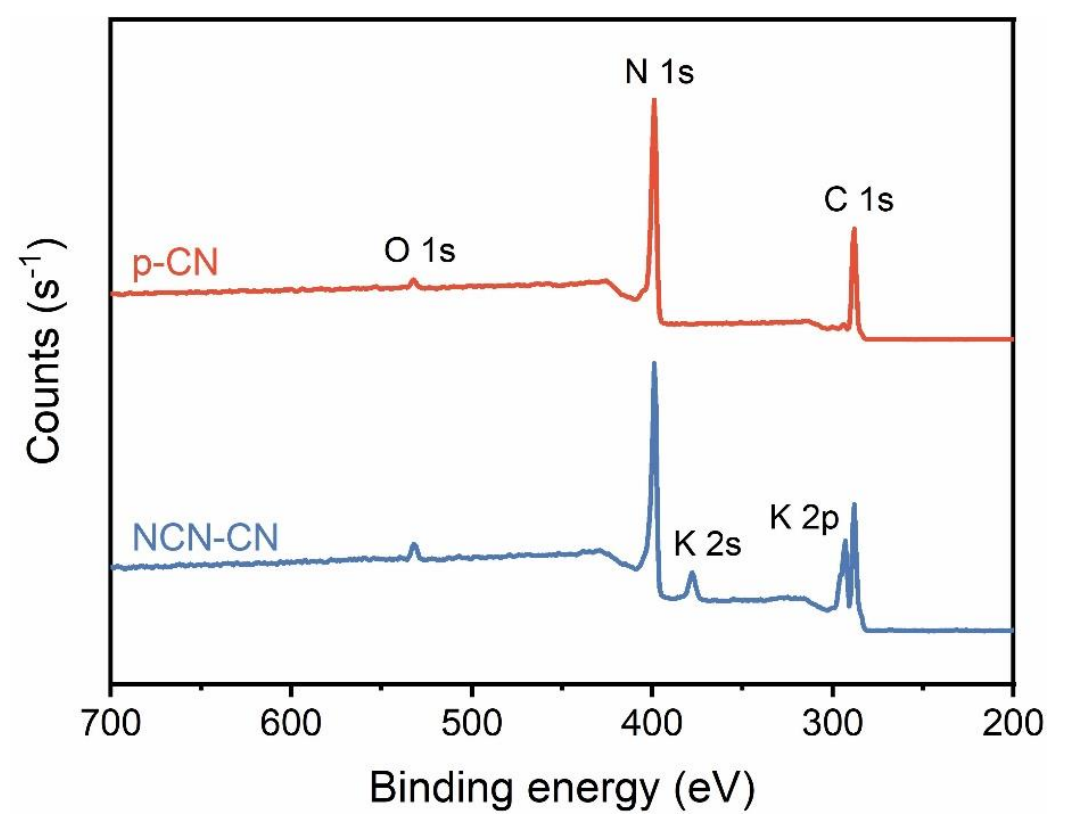

Figure S1. XPS survey scan spectra of $\mathrm{p}-\mathrm{CN}$ and $\mathrm{NCN}-\mathrm{CN}$.

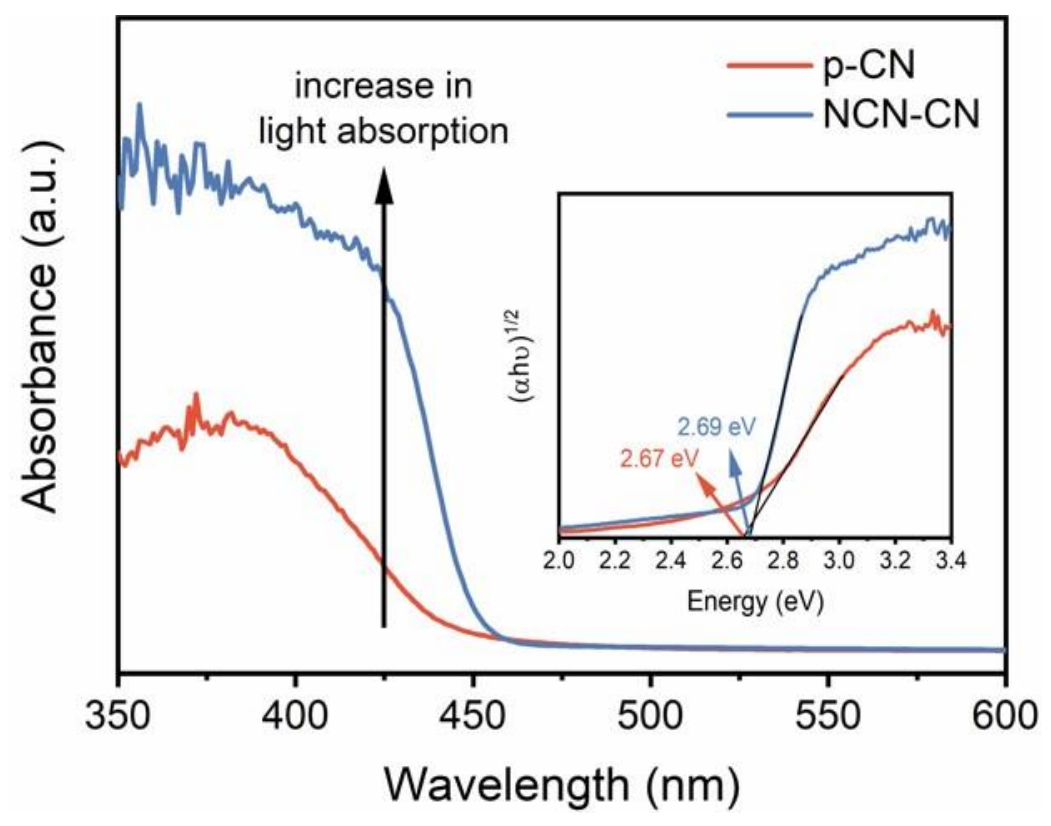

Figure S2. UV-vis spectra of $\mathrm{p}-\mathrm{CN}$ and $\mathrm{NCN}-\mathrm{CN}$ along with the Tauc plot in the inset for band gap energy calculations. 


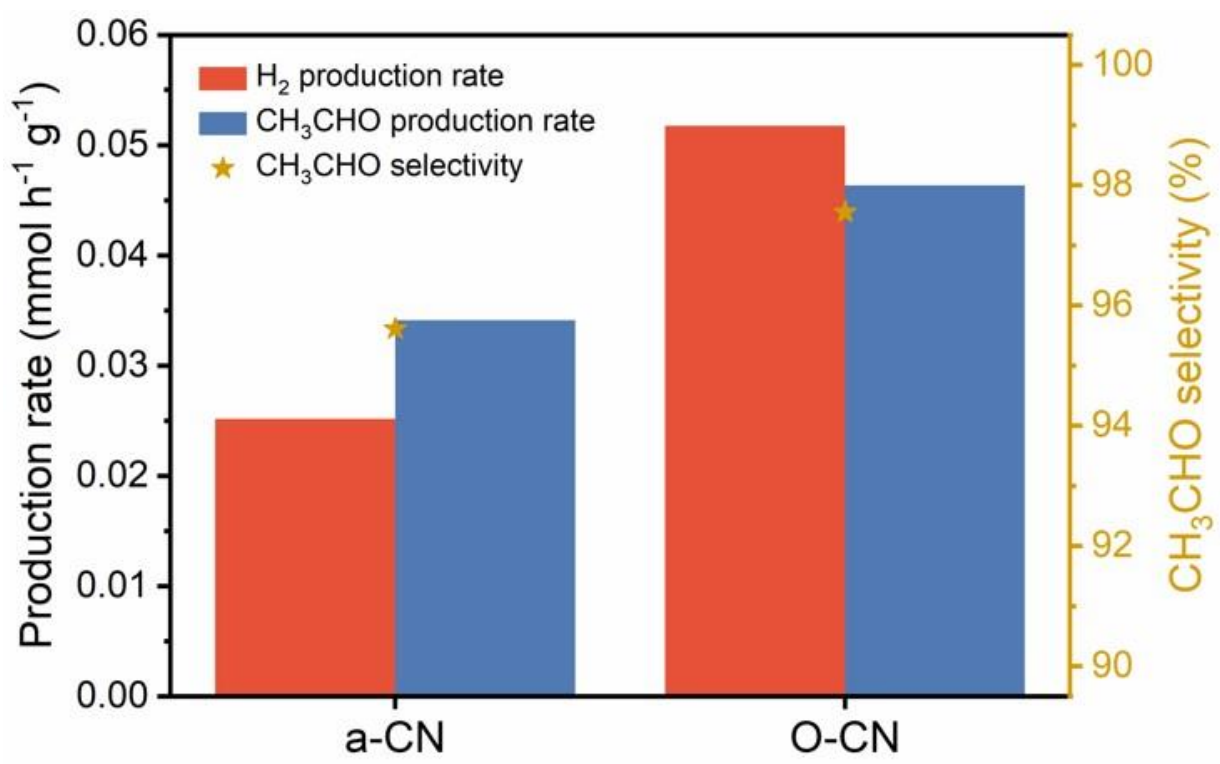

Figure S3. $\mathrm{H}_{2}$ and acetaldehyde production rates and acetaldehyde selectivity for a-CN and $\mathrm{O}-\mathrm{CN}$ in the absence of cocatalyst.
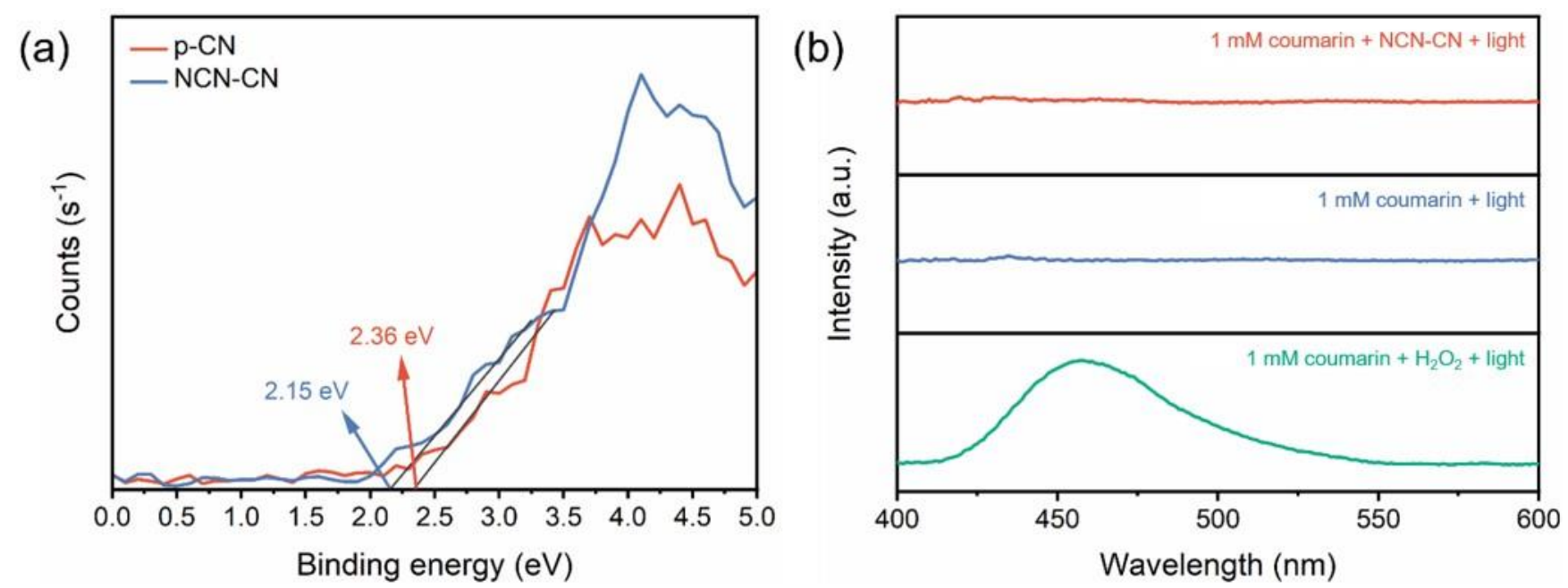

Figure S4. (a) Valence band XPS spectra of p-CN and NCN-CN. (b) Fluorescence spectra for hydroxyl radical detection using coumarin tests. The red curve represents spectra after light illumination of $1 \mathrm{mM}$ coumarin in $\mathrm{NCN}-\mathrm{CN}$ suspension, the blue curve represents control spectra after light illumination of 1 $\mathrm{mM}$ coumarin solution without NCN-CN, and the green curve represents control spectra after photolysis of $1 \mathrm{mM} \mathrm{H}_{2} \mathrm{O}_{2}$ in $1 \mathrm{mM}$ coumarin solution without $\mathrm{NCN}-\mathrm{CN}$. 


\section{$\mathrm{Ni}(1) / \mathrm{NCN}-\mathrm{CN} \quad \mathrm{Ni}(3) / \mathrm{NCN}-\mathrm{CN} \quad \mathrm{Ni}(5) / \mathrm{NCN}-\mathrm{CN}$}

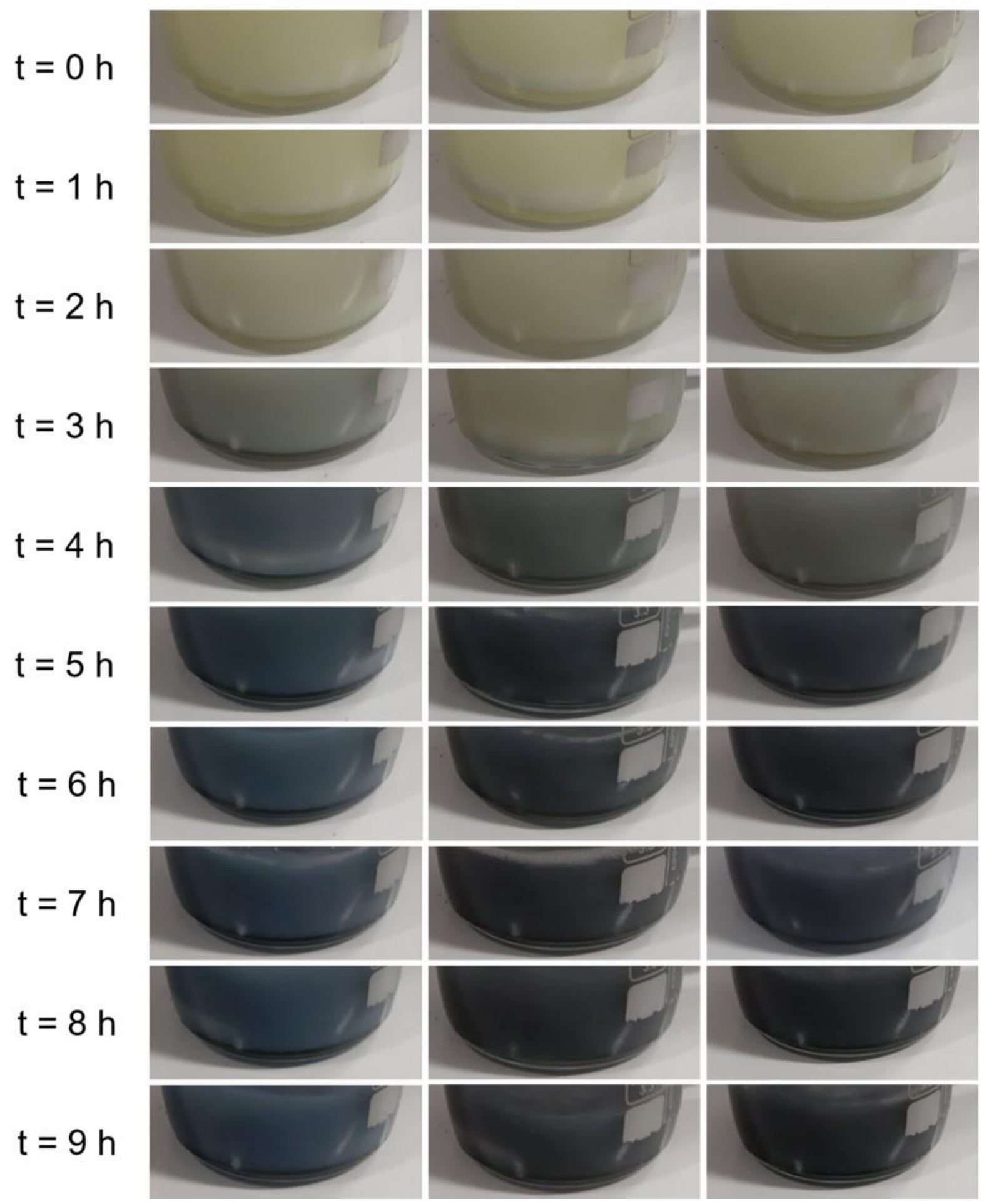

Figure S5. Digital photographs of the reaction mixtures of $\mathrm{Ni}(1) / \mathrm{NCN}-\mathrm{CN}, \mathrm{Ni}(3) / \mathrm{NCN}-\mathrm{CN}$, and $\mathrm{Ni}(5) / \mathrm{NCN}-\mathrm{CN}$ at different reaction time. 
(a)

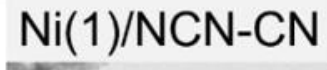

\section{$\underline{200} \mathrm{~nm}$}

(c) $\mathrm{Ni}(3) / \mathrm{NCN}-\mathrm{CN}$

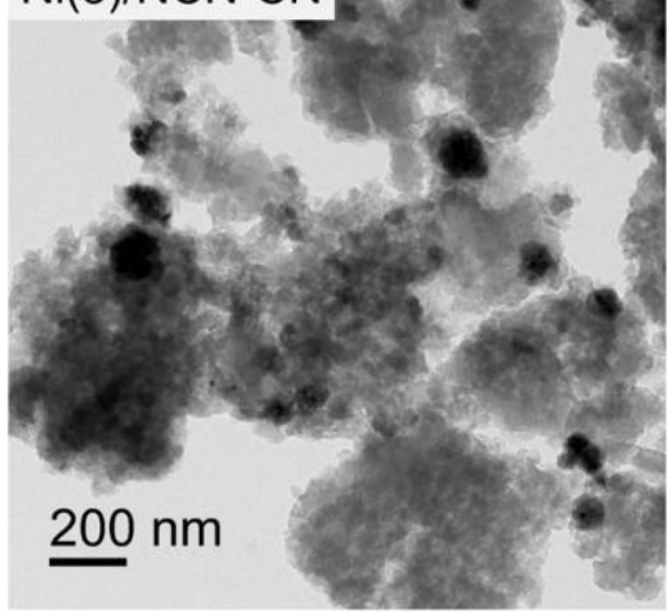

(e) $\mathrm{Ni}(5) / \mathrm{NCN}-\mathrm{CN}$

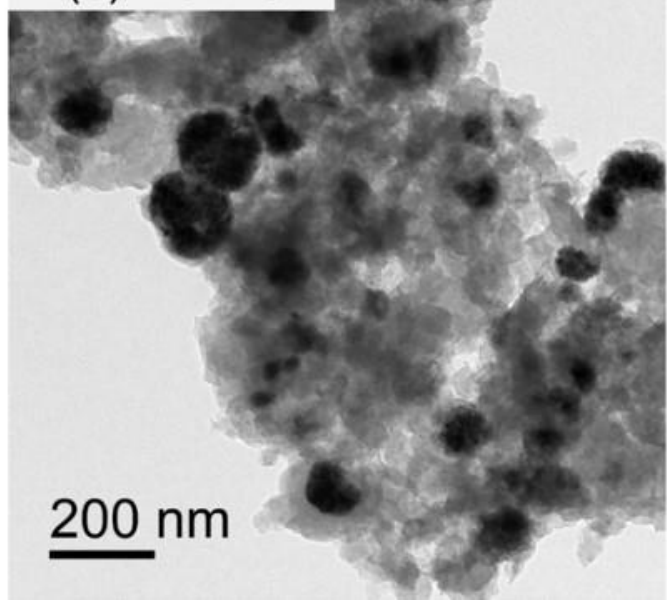

(b)

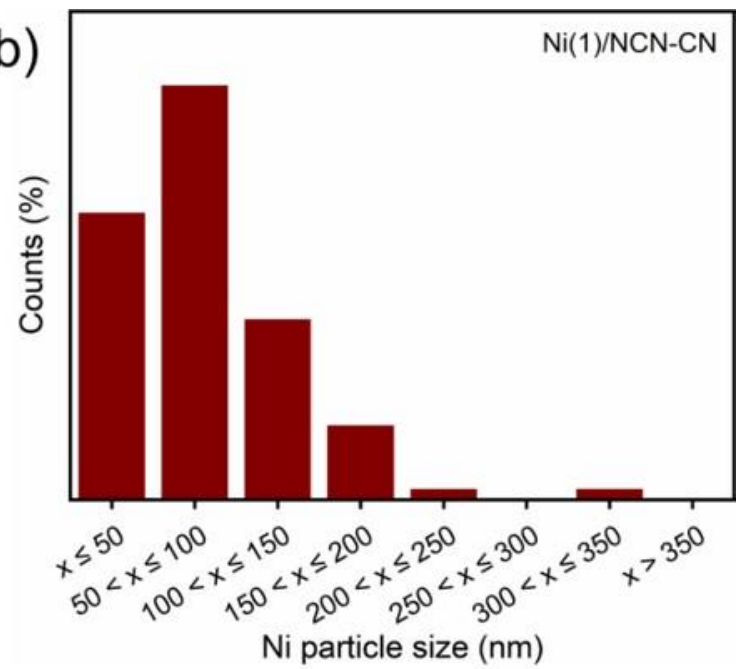

(d)

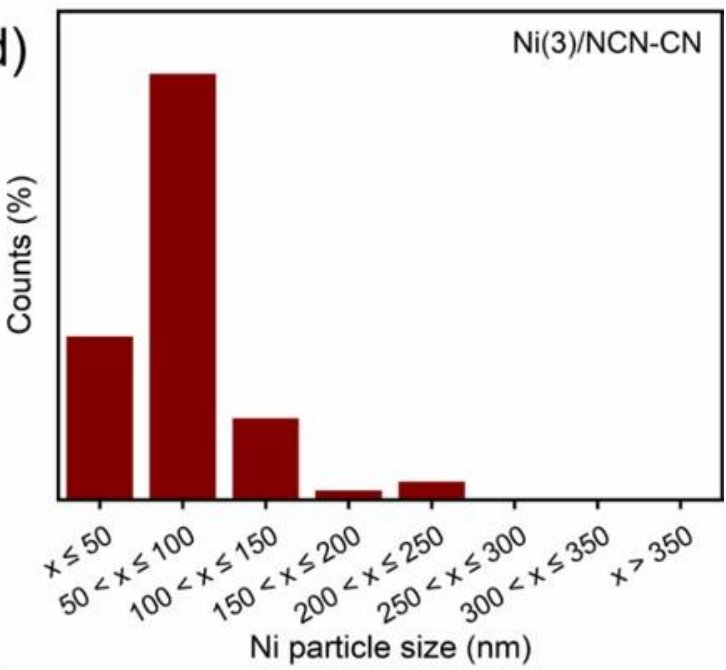

(f)

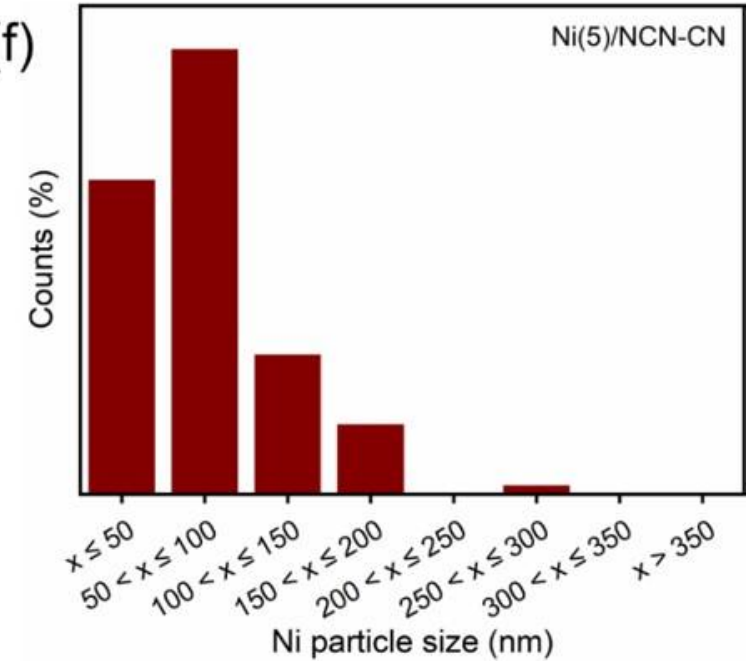

Figure S6. Low-magnification TEM images and Ni particle size distribution histograms of (a-b) $\mathrm{Ni}(1) / \mathrm{NCN}-\mathrm{CN}$, (c-d) $\mathrm{Ni}(3) / \mathrm{NCN}-\mathrm{CN}$, and (e-f) Ni(5)/NCN-CN. 

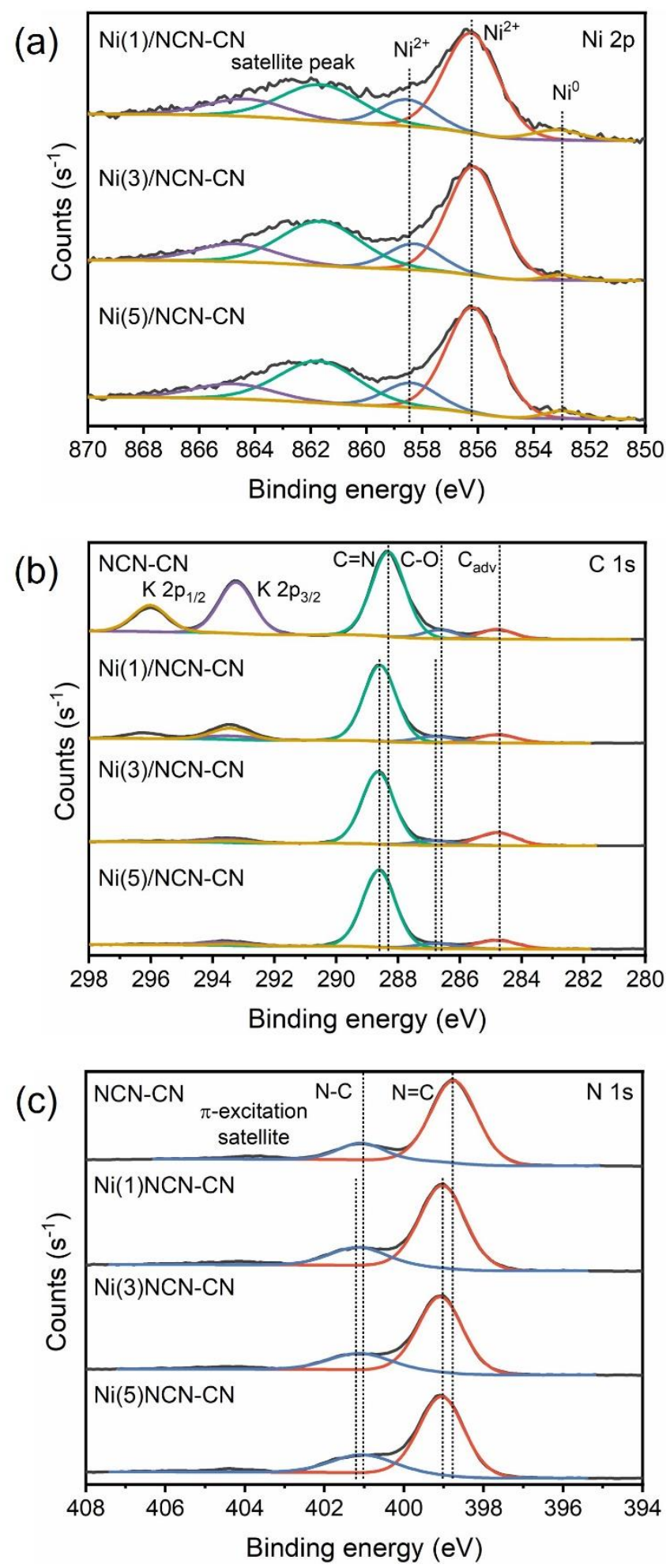

Figure S7. (a) High-resolution Ni 2p XPS spectra of Ni(1)/NCN-CN, Ni(3)/NCN-CN, and Ni(5)/NCNCN. (b) High-resolution C 1s XPS spectra and (c) high-resolution N 1s XPS spectra of Ni(1)/NCN-CN, $\mathrm{Ni}(3) / \mathrm{NCN}-\mathrm{CN}$, and $\mathrm{Ni}(5) / \mathrm{NCN}-\mathrm{CN}$ compared to as-prepared $\mathrm{NCN}-\mathrm{CN}$. 


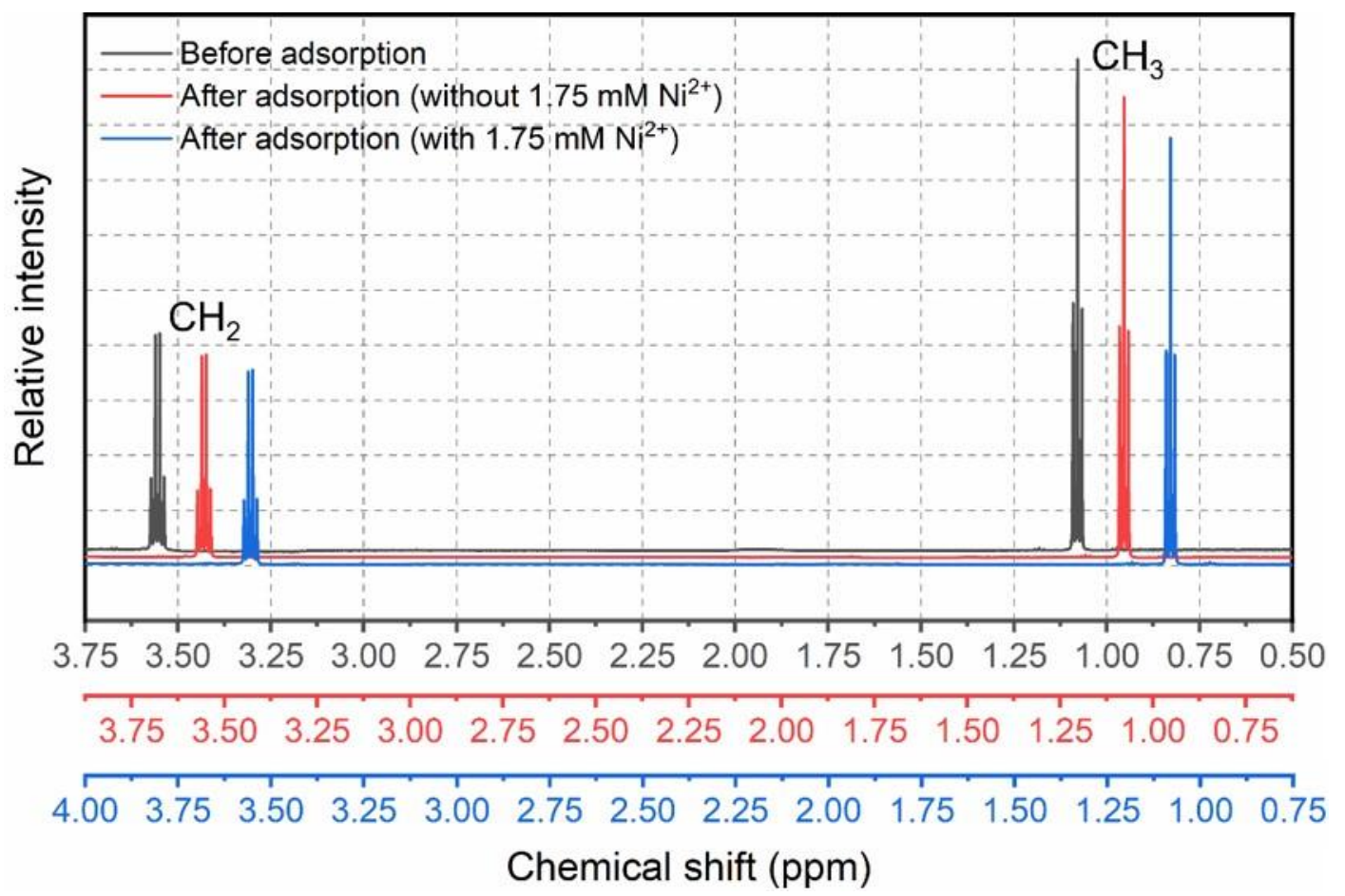

Figure S8. ${ }^{1} \mathrm{H}$ NMR spectra of ethanol solution during adsorption experiments on $\mathrm{Ni} / \mathrm{NCN}-\mathrm{CN}$ without and with additional $\mathrm{Ni}^{2+}$ in solution. 
(a)

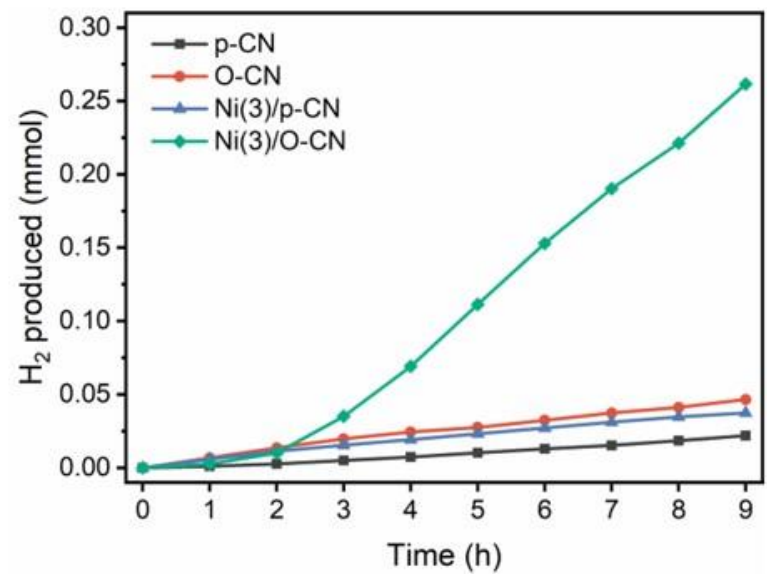

(b)

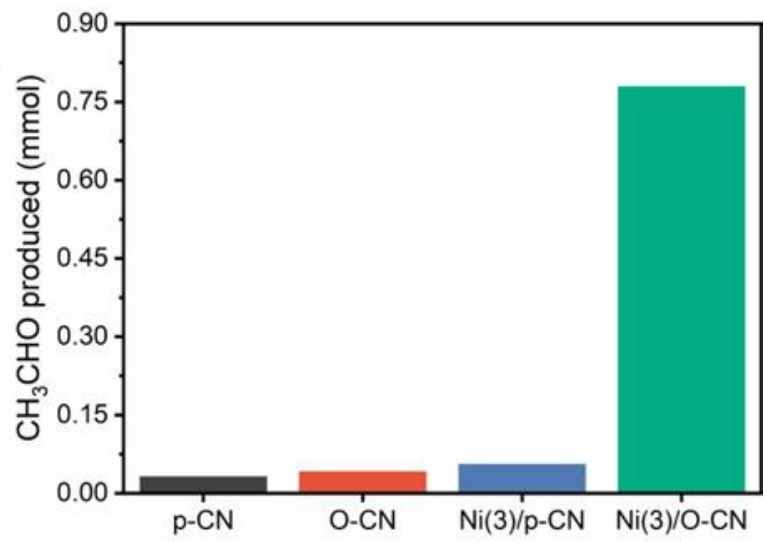

Figure S9. (a) Time-dependent $\mathrm{H}_{2}$ evolution profiles and (b) acetaldehyde productivity after $9 \mathrm{~h}$ of reaction on $\mathrm{p}-\mathrm{CN}, \mathrm{O}-\mathrm{CN}, \mathrm{Ni}(3) / \mathrm{p}-\mathrm{CN}$, and $\mathrm{Ni}(3) / \mathrm{O}-\mathrm{CN}$.
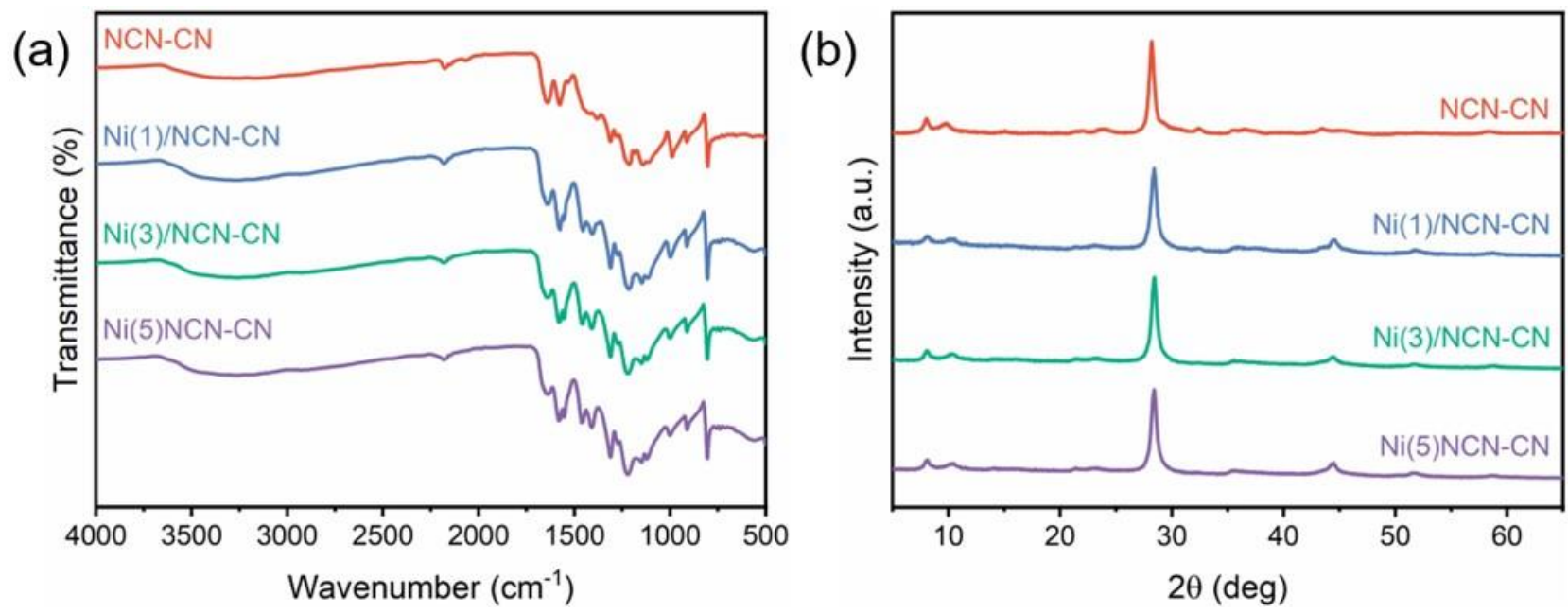

Figure S10. (a) XRD patterns and (b) FTIR spectra of Ni(1)/NCN-CN, Ni(3)/NCN-CN, and $\mathrm{Ni}(5) / \mathrm{NCN}-\mathrm{CN}$ compared to as-prepared NCN-CN. 


\section{References}

1. Lau, V. W.; Moudrakovski, I.; Botari, T.; Weinberger, S.; Mesch, M. B.; Duppel, V.; Senker, J.; Blum, V.; Lotsch, B. V. Rational Design of Carbon Nitride Photocatalysts by Identification of Cyanamide Defects as Catalytically Relevant Sites. Nat. Commun. 2016, 7, 12165.

2. Meng, N.; Ren, J.; Liu, Y.; Huang, Y.; Petit, T.; Zhang, B. Engineering Oxygen-Containing and Amino Groups into Two-Dimensional Atomically-Thin Porous Polymeric Carbon Nitrogen for Enhanced Photocatalytic Hydrogen Production. Energy Environ. Sci. 2018, 11 (3), 566-571.

3. Toe, C. Y.; Tan, H. L.; Boyer, C.; Rawal, A.; Thickett, S. C.; Scott, J.; Amal, R.; Ng, Y. H. PhotoDriven Synthesis of Polymer-Coated Platinized $\mathrm{ZnO}$ Nanoparticles with Enhanced Photoelectrochemical Charge Transportation. J. Mater. Chem. A 2017, 5 (9), 4568-4575.

4. Fan, Y.; Zhou, W.; Qiu, X.; Li, H.; Jiang, Y.; Sun, Z.; Han, D.; Niu, L.; Tang, Z. Selective Photocatalytic Oxidation of Methane by Quantum-Sized Bismuth Vanadate. Nat. Sustainability 2021, 4 (6), 509-515.

5. Qureshi, M.; Takanabe, K. Insights on Measuring and Reporting Heterogeneous Photocatalysis: Efficiency Definitions and Setup Examples. Chem. Mater. 2016, 29 (1), 158-167.

6. Kresse, G.; Hafner, J. Ab Initio Molecular-Dynamics Simulation of the Liquid-Metal-AmorphousSemiconductor Transition in Germanium. Phys. Rev. B 1994, 49 (20), 14251-14269.

7. Kresse, G.; Hafner, J. Efficient Iterative Schemes for Ab Initio Total-Energy Calculations Using a Plane-Wave Basis Set. Phys. Rev. B 1996, 54 (16), 11169-11186.

8. Kresse, G.; Joubert, D. From Ultrasoft Pseudopotentials to the Projector Augmented-Wave Method. Phys. Rev. B 1999, 59 (3), 1758-1775.

9. Perdew, J. P.; Burke, K.; Matthias, E. Generalized Gradient Approximation Made Simple. Phys. Rev. Lett. 1996, 77 (18), 3865-3868.

10. Xia, X.; Tang, L.; Ji, H.; Kang, L.; Wei, Z.; Lou, S.; Xie, J.; Tang, B. Syn ergistic Enhancement of Photocatalytic $\mathrm{H}_{2}$ Production by $\mathrm{Ni}$ Decorated 2D Bubble-like Carbon Nitride. Int. J. Hydrogen Energy 2021, 46 (45), 23311-23321.

11. Kong, L.; Dong, Y.; Jiang, P.; Wang, G.; Zhang, H.; Zhao, N. Light-Assisted Rapid Preparation of a Ni/g- $\mathrm{C}_{3} \mathrm{~N}_{4}$ Magnetic Composite for Robust Photocatalytic $\mathrm{H}_{2}$ Evolution from Water. J. Mater. Chem. A 2016, 4 (25), 9998-10007. 
12. Indra, A.; Acharjya, A.; Menezes, P. W.; Merschjann, C.; Hollmann, D.; Schwarze, M.; Aktas, M.; Friedrich, A.; Lochbrunner, S.; Thomas, A.; Driess, M. Boosting Visible-Light-Driven Photocatalytic Hydrogen Evolution with an Integrated Nickel Phosphide-Carbon Nitride System. Angew. Chem., Int. Ed. 2017, 56 (6), 1653-1657.

13. Jin, Z.; Wang, H.; Ma, Q. High Electron Conductivity of $\mathrm{Ni} / \mathrm{Ni}_{3} \mathrm{C}$ Nanoparticles Anchored on CRich Graphitic Carbon Nitride for Obviously Improving Hydrogen Generation. Ind. Eng. Chem. Res. 2020, 59 (19), 8974-8983.

14. Kasap, H.; Caputo, C. A.; Martindale, B. C.; Godin, R.; Lau, V. W.; Lotsch, B. V.; Durrant, J. R.; Reisner, E. Solar-Driven Reduction of Aqueous Protons Coupled to Selective Alcohol Oxidation with a Carbon Nitride-Molecular Ni Catalyst System. J. Am. Chem. Soc. 2016, 138 (29), 9183-9192.

15. Xu, Y.; Du, C.; Zhou, C.; Yang, S. A New Ni-Diaminoglyoxime-g- $\mathrm{C}_{3} \mathrm{~N}_{4}$ Complex Towards Efficient Photocatalytic Ethanol Splitting via a Ligand-to-Metal Charge Transfer (LMCT) Mechanism. Chem. Commun. 2020, 56 (52), 7171-7174. 